\title{
PENINGKATAN KUALITAS CITRA DENGAN METODE FUZZY POSSIBILITY DISTRIBUTION
}

\author{
Sugiarti \\ sugiarti_fikumi@ymail.com \\ Universitas Muslim Indonesia
}

\begin{abstract}
Abstrak
Peningkatan kualitas citra merupakan salah satu proses awal dalam peningkatan mutu citra. Peningkatan mutu citra diperlukan karena seringkali citra yang dijadikan objek pembahasan mempunyai kualitas yang buruk, misalnya citra mengalami derau, kabur [2].Pada penelitian ini, peningkatkan kualitas citra menggunakan teknik image enhancement, berupa proses perbaikan citra dengan meningkatkan kualitas citra baik kontras maupun kecerahan.Tujuan dari penelitian adalah meningkatkan kualitas citra menggunakan pendekatan logika fuzzy dengan menggunakan 5 parameter, yaitu $\alpha, \beta_{1}, \gamma, \beta_{2}$ dan max. Penggunaan metode fuzzy possibility bertujuan menurunkan tingkat keabuan pixel yang memiliki nilai keabuan di antara $\beta_{1}$ dan $\beta_{2}$. Pada penelitian ini dilakukan peningkatan kualitas citra, sehingga tampilan objek lebih terang dan jelas sehingga dapat memudahkan proses segmentasi yaitu pemisahan objek yang akan diteliti dengan background.
\end{abstract}

Kata kunci: kualitas, citra, fuzzy possibility, pixel, segmentasi

\section{Pendahuluan}

Citra (image) sebagai salah satu komponen multimedia yang memegang peranan penting sebagai bentuk informasivisual.Citra mempunyai karakteristik yang tidak dimiliki oleh data teks, yaitu citra kaya dengan informasi.Ada sebuah peribahasa yang berbunyi "sebuah gambar bermakna lebih dari seribu kata".Maksudnya tentu sebuah gambar dapat memberikan informasi yang lebih banyak daripada informasi tersebut disajikan dalam bentuk kata-kata (tekstual). Meskipun sebuah citra kaya informasi, namun seringkali citra yang kita miliki mengalami penurunan mutu (degradasi), misalnya mengandung cacat atau derau (noise), warnanya terlalu kontras, kurang tajam, kabur (blurred), dan sebagainya. Tentu saja citra semacam ini menjadi lebih sulit diinterpretasi karena informasi yang disampaikan oleh citra tersebut menjadi berkurang. Agar citra yang mengalami gangguan mudah diinterpretasi (baik oleh manusia maupun mesin), maka citra tersebut perlu dimanipulasi menjadi citra lain yang kualitasnya lebih baik menggunakan teknik pengolahan citra.[1]

Pengolahan citra merupakan suatu sistem dimana proses dilakukan dengan masukan citra dan hasilnya juga berupa citra. Peningkatan kualitas citra merupakan salah satu proses awal dalam peningkatan kualitas citra. Peningkatan kualitas citra diperlukan karena citra mempunyai kualitas yang buruk, misalnya citra mengalami derau atau kabur. Proses pengolahan citra yang termasuk dalam kategori peningkatan kualitas citra terdiri dari proses-proses yang bertujuan memperbaiki kualitas citra. Dalam hal ini ada beberapa teknik yang digunakan,yaitu antara lain image enhancement, berupa proses perbaikan citra,image restoration, proses memperbaiki model citra, color image processing.[2]

Pengolahan Citra adalah pemrosesan citra, khususnya dengan menggunakan komputer, menjadi citra yang kualitasnya lebih baik. Pengolahan citra bertujuan memperbaiki kualitas citra agar mudah diinterpretasi oleh manusia atau mesin dalam hal ini komputer. Teknik- teknik pengolahan citra mentransformasikan citra menjadi citra lain. Jadi, masukannya adalah citra dan keluarannya juga citra yang berkualitas lebih baik daripada citra masukan.[2]

Berdasarkan latar belakang masalah di atas, maka yang menjadi rumusan masalah adalah bagaimana melakukan perbaikan citra pada gambar yang menjadi data inputan dan bagaimana menerapkan metode fuzzy possibityuntuk perbaikan kualitas citra.

Penelitian ini terbatas pada data inputan yang berupa citra berwarna (RGB) kemudian dilakukan proses grayscale yaitu mengubah cita berwarna menjadi keabuan. Hasil dari proses grayscaleselanjutnya dilakukan proses perbaikan kualitas citra dengan metodefuzzypossibility.

Tujuan penelitian adalahmeningkatkan kualitas citra dengan menggunakan pendekatan logika fuzzypossibilitysehingga tampilan objek lebih jelas dan lebih mudah dilakukan proses segmentasi.

\section{Metode}

Metode yang digunakan dalam penelitian initerdiri dari bebrapa tahapan yang diawali dengan pengumpulan data. Pada tahap ini dilakukan pengumpulan data terhadap beberapa perangkat dan konsep yang akan digunakan dalam penelitian ini. Data input diperoleh dari internet berupa citra kanker kulit melanoma dan citra kulit luka biasa(bukan melanoma).Tahap kedua yaitu 
analisis.terhadap rumusan masalah dan batasan masalah dalam penelitian serta spesifikasi sistem yang akan dibuat sesuai dengan batasan yang ada. Tahap ketiga perancangan aplikasi sesuai hasil analisis terdiri dari perancangan arsitektur sistem, antarmuka, dan modul lainnya yang akan berintegrasi dalam suatu sistem. Tahap keempat testing aplikasi berupa pengujian terhadap sistem yang telah diimplementasikanndengan memasukkan data pengujian tertentu.Tahap terakhir implementasi sesuai dengan hasil perancangan dengan menggunakan perangkat yang sudah dikumpulkan pada tahap sebelumnya.

\section{Grayscale}

Grayscalling adalah teknik yang digunakan untuk mengubah citra berwana (RGB) menjadi bentuk grayscale atau tingkat keabuan.Dengan pengubahan ini, matriks penyusun citra yang sebelumnya 3 matriks akan berubah menjadi 1 matriks saja[3].

Citra grayscale disebut juga citra satu kanal, karena warnanya hanya ditentukan oleh satu fungsi intensitas saja, artinya mempunyai skala abu dari 0 sampai 255 , yang dalam hal ini nilai intensitas 0 menyatakan hitam, nilai intensitas 255 menyatakan putih (Munir, 2004)[4].

Dalam komputasi, suatu citra digital grayscale atau greyscale adalah suatu citra dimana nilai dari setiap pixel merupakan sampel tunggal.Citra yang ditampilkan dari citra jenis ini terdiri atas warna abu-abu, bervariasi pada warna hitam pada bagian yang intensitas terlemah dan warna putih pada intensitas terkuat.Citra grayscale berbeda dengan citra hitam-putih, dimana pada konteks komputer, citra hitam putih hanya terdiri atas 2 warna saja yaitu hitam dan putih saja.

Pada citra grayscale warna bervariasi antara hitam dan putih, tetapi variasi warna diantaranya sangat banyak. Citra grayscale seringkali merupakan perhitungan dari intensitas cahaya pada setiap pixel pada spektrum elektromagnetik single band .Citra grayscale disimpan dalam format 8 bit untuk setiap sampel pixel, yang memungkinkan sebanyak 256 intensitas. Format ini sangat membantu dalam pemrograman karena manipulasi bit yang tidak terlalu banyak. Pada aplikasi lain seperti pada aplikasi medical imaging dan remote sensing biasa juga digunakan format 10,12 maupun 16 bit. Citra grayscale disimpan dalam format 8 bit untuk setiap sampel pixel, yang memungkinkan sebanyak 256 intensitas.

\section{Kualitas Citra}

1. Kecerahan Gambar (Image Brightness )

Kecerahan/kecermelangan gambar dapat diperbaiki dengan menambahkan atau mengurangkan sebuah konstanta kepada atau dari setiap pixel di dalam citra. Nilai pixel hasil pengubahan mungkin lebih kecil atau sama dengan derajat keabuan minimum (0) atau lebih besar sama dengan derajat keabuan maksimum. Karena itu, pixel tersebut perlu dilakukan clipping ke nilai keabuan minimum atau ke nilai keabuan maximum [4].

\section{Peregangan Kontras (Contrast Stretching)}

\subsection{Citra Kontras-Rendah}

Citra Kontras-Rendah dicirikan dengan sebagian besar komposisi citranya adalah terang atau sebagian besar gelap. Tetapi, mungkin saja suatu citra tergolong Kontras-Rendah meskipun tidak terlalu terang atau tidak terlalu gelap bila semua pengelompokan nilai keabuan berada ditengah-tengah.Citra Kontras-Rendah dapat diperbaiki kualitasnya dengan operasi peregangan kontras. Melaui operasi ini, nilai-nilai keabuan pixel akan merentang dari 0 sampai 255 ( pada citra 8-bit).

2.2. Citra Kontras-Bagus

Citra Kontras-Bagus memperlihatkan jangkauan nilai keabuan yang lebar tanpa ada nilai keabuan yang mendominasi.

\subsection{Citra Kontras-Tinggi}

Citra Kontras-Tinggi memiliki nilai jangkauan nilai keabuan yang lebar, tetapi terdapat area yang lebar yang didominasi oleh warna gelap dan area yang lebar yang didominasi oleh warna terang [4].

\section{Penajaman (Image Sharpening)}

Penajaman Citra bertujuan memperjelas tepi pada objek di dalam citra.Penajaman Citra dilakukan dengan melewatkan citra pada penapis lolos-tinggi (high-pass filter).Karena penajaman citra lebih berpengaruh pada tepi (edge) objek, maka penajaman citra disebut juga penajaman tepi (edge sharpening) atau peningkatan kualitas tepi (edge enhancement).Akibatnya, pinggiran objek terlihat lebih tajam dibandingkan sekitarnya[4]. 


\section{Fuzzy Possibility Distribution}

Perbaikan kualitas citra (image enhancement) merupakan sebuah proses awal dalam pengolahan citra (image preprocessing). Salah satu penyebab terjadinya perbaikan kualitas citra karena citra seringkali mengalami penurunan mutu (degradasi) disebabkan karena citra cacat (noise). Noise atau derau adalah titik pada citra yang sebenarnya bukan merupakan bagian pada citra tersebut, melainkan tercampur karena suatu sebab[5].

Preprocessing untuk peningkatan kualitas citra menggunakan Algoritma Possibility Distribution bertujuan untuk peningkatan kualitas citra menggunakan pendekatan logika fuzzy dengan menggunakan 5 parameter, yaitu $\alpha, \beta_{1}, \gamma, \beta_{2}$ dan max.

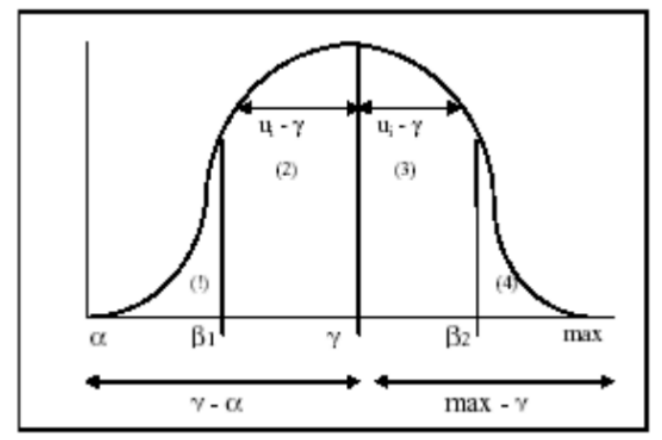

Gambar 1. Fungsi possibility distribution

Dari parameter yang dibutuhkan, a merepresentasikan nilai minimum distribusi, $Y$ merepresentasikan nilai rata-rata distribusi dan max merepresentasikan nilai maksimum distribusi. Fungsi transformasi fuzzy untuk mendapatkan keseluruhan nilai didefinisikan $\left(\alpha=\min , \beta_{1}=(\alpha+\gamma) / 2\right.$, $\mathrm{y}=$ mean, $\beta_{2}=(\max +\mathrm{y}) / 2$, $\left.\max =\max \right)$.

Tujuan dari penggunaan algoritma possibility distribution dalam peningkatan kualitas citra adalah untuk menurunkan tingkat keabuan pixel yang memiliki nilai keabuan di antara $\beta_{1}$ dan $\beta_{2}$.Cara yang dilakukan adalah memberikan nilai intensitas baru di pixel di antara $\beta_{1}$ dan $\gamma, \gamma$ dan $\beta_{2}$ dengan nilai direksi yang berlawanan menuju nilai mean $\gamma$. Aturan fuzzy di bawah ini digunakan untuk melakukan peningkatan kontras citra berdasarkan [6] :

1. Rule-1: if $\alpha \leq u i \leq \beta_{1}$ then $P=2\left(\frac{u i-\alpha}{y-\alpha}\right)^{2}$

2. Rule-2: if $\beta_{1} \leq u i \leq y$ then $P=1-2\left(\frac{u i-\gamma}{y-\alpha}\right)^{2}$

3. Rule-3: if $\gamma \leq u i \leq \beta_{2}$ then $P=1-2\left(\frac{u i-\gamma}{\max -\gamma}\right)^{2}$

4. Rule-4: if $\beta_{2} \leq$ ui $\leq$ max then $P=2\left(\frac{u i-\gamma}{\max -\gamma}\right)^{2}$

dimana $u i=f(x, y)$ adalah intensitas piksel ke-i.

Algoritma possibility distribution digambarkan sebagai berikut[6] :

1. Langkah-1: Inisialisasi Parameter

Set $\beta_{1}=(\min +$ mean $) / 2$

Set $\beta_{2}=(\max +$ mean $) / 2$

2. Langkah-2: Fuzzifikasi

Untuk semua piksel (i, j) dalam gambar

1. if $(\operatorname{data}(\mathrm{i}, \mathrm{j}) \geq \min ) \& \&\left(\operatorname{data}(\mathrm{i}, \mathrm{j})<\beta_{1}\right.$ graybaru $\left((\mathrm{i}, \mathrm{j})=2 *\left(((\mathrm{data}(\mathrm{i}, \mathrm{j})-\min ) /(\text { means }-\min ))^{\wedge} 2\right)\right)$

2. if $\left(\operatorname{data}(\mathrm{i}, \mathrm{j}) \geq \beta_{1}\right) \& \&(\operatorname{data}(\mathrm{i}, \mathrm{j})<$ means

$$
\text { graybaru }\left((\mathrm{i}, \mathrm{j})=1-\left(2 *\left(((\mathrm{data}(\mathrm{i}, \mathrm{j})-\text { means }) /(\text { means }-\min ))^{\wedge} 2\right)\right)\right.
$$

3. if $(\operatorname{data}(\mathrm{i}, \mathrm{j}) \geq$ means $) \& \&\left(\operatorname{data}(\mathrm{i}, \mathrm{j})<\beta_{2}\right.$ $\operatorname{graybaru}\left((\mathrm{i}, \mathrm{j})=1-\left(2 *\left(((\mathrm{data}(\mathrm{i}, \mathrm{j})-\text { means }) /(\max -\text { means }))^{\wedge} 2\right)\right)\right.$

4. if $\left(\operatorname{data}(\mathrm{i}, \mathrm{j}) \geq \beta_{2}\right) \& \&(\operatorname{data}(\mathrm{i}, \mathrm{j})<\max$

3. Langkah-3: Modifikasi

$$
\text { graybaru }\left((i, j)=\left(2 *\left(((\operatorname{data}(i, j)-\text { means }) /(\max -\text { means }))^{\wedge} 2\right)\right)\right.
$$


fuzzydata2 $(i, j)=\operatorname{graybaru}(i, j)^{\wedge} 2$

\section{Step-4: Defuzzification}

Untuk semua piksel (i, j) dalam gambar

kualitascitra $(i, j)=$ fuzzydata2 $(i, j) * \operatorname{data}(i, j)$

\section{Hasil dan Pembahasan}

Aplikasi yang dirancang dengan menggunakan metode fuzzy possibility distributiondapat meningkatkan kualitas citra sehingga memudahkan proses segmentasi. Adapun tahapan perancangan sistem sebagai berikut :

1. Tahap pertama untuk pegolahan citra adalah preprocesing dengan mengubah citra asli berwarna/ RGB menjadi citra grayscale (keabuan).
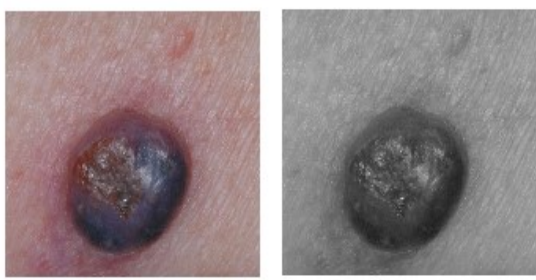

Gambar 2. Perubahan dari citra berwarna menjadi citra grayscale (keabuan)

2. Berdasarkan hasil grayscale pada gambar 2 di atas berikutnya dilakukan perbaikan kualitas citra dengan algoritma possibility distribution.

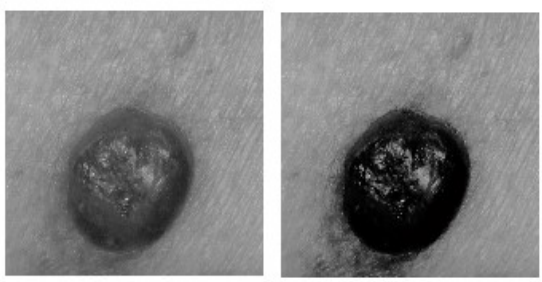

Gambar 3. Perbaikan kualitas citra dari citra grayscale

Berdasarkan poin ke 1 di atas dapat kita lihat yang menjadi data inputan adalah citra kanker kulit berwarna.Kemudian citra berwarna diubah menjadi citra grayscale sehingga citra tampak keabuan. Pada poin ke 2 tampak dengan jelas perubahan yang terjadi setelah dilakukan proses perbaikan kualitas citra, dimana area objek yang mau diteliti lebih jelas batasannya. Perbaikan kualitas citra (image enhancement) dari citra grayscale bertujuan menghasilkan citra dengan kualitas yang lebih baik dibandingkan dengan citra grayscale semula sehingga hasil segmentasi selanjutnya lebih baik.

\section{Kesimpulan dan Saran Kesimpulan}

Dari penelitian yang telah dilakukan, maka dapat ditarik kesimpulan bahwa perbaikan kualitas citra perlu dilakukan pada citra yang memiliki kualitas buruk seperti citra yang kabur agar menghasilkan output yang lebih bagus dan berkualitas. Penggunaan algoritma possibility distributiondapat menghasilkan citra yang lebih jelas dan terang sehingga proses segmentasi lebih mudah dilakukan.

\section{Saran}

Pada penelitian berikutnya diharapkan dapat menggunakan metode yang lain kemudian membandingkan hasilnya, kemudian dilakukan analisis pada metode tersebut, sehingga pada penelitian selanjutnya dapat menggunakan metode yang lebih tepat agar dapat menghasilkan output yang lebih baik.

\section{Daftar Pustaka}

[1] Nur Wakhidah. 2012. Perbaikan Kualitas Citra Menggunakan Metode Contrast Stretching (Improvement of image quality using a method Contrast Stretching). Fakultas Teknologi Informasi dan Komunikasi Universitas Semarang. 


\section{ILKOM Jurnal Ilmiah Volume 10 Nomor 1 April 2018}

[2] Harvei Desmon Hutahaean. 2010. Teknik Penajaman Citra Digital Dengan Menggunakan Metode Contrast Streching.STMIK Budi Darma Medan.

[3] Rinaldi Munir. 2010. Pengantar Pengolahan Citra. ITB.

[4] Mukhamad Nurkamid dan Sutejo. 2012. Metode Kecerahan Citra Kontras Citra Dan Penajaman Citra Untuk Peningkatan Mutu Citra.

[5] M. N. . Fachrurrozie, B. Amaliah, dan I. Arieshanti. 2010. Diagnosa Awal Citra Melanoma Menggunakan Metode Svmboosting.

[6] A. E. Hassanien dan A. Badr. 2003. A Comparative Study on Digital Mamography Enhancement Algorithms on Fuzzy Theory," Studies In Informatic and Control, vol. Vol. 1. 